\title{
Word recognition in two languages and orthographies: English and Greek
}

\author{
HELENA-FIVI CHITIRI \\ St. Francis Xavier University, Antigonish, Nova Scotia, Canada \\ and \\ DALE M. WILLOWS \\ Ontario Institute for Studies in Education, Toronto, Ontario, Canada
}

\begin{abstract}
Word recognition processes of monolingual readers of English and of Greek were examined with respect to the orthographic and syntactic characteristics of each language. Because of Greek's direct letter-to-sound correspondence, which is unlike the indirect representation of English, the possibility was raised of a greater influence of the phonological code in Greek word recognition. Because Greek is an inflected language, whereas English is a word order language, it was also possible that syntax might influence word recognition patterns in the two languages differentially. These cross-linguistic research questions were investigated within the context of a letter cancellation paradigm. The results provide evidence that readers are sensitive to both the orthographic and the linguistic idiosyncracies of their language. The results are discussed in terms of the orthographic depth hypothesis and the competition model.
\end{abstract}

In this research, we examined word recognition in English and Greek, two languages with different orthographies and syntactic characteristics. We examined the relationship of orthography to the role of the phonological code in word recognition as it is exemplified in the processing of syllabic and stress information. To study the role of the syntactic system, we investigated whether word recognition patterns in the two languages would differ when readers were processing function words and the different parts of content words. Of special importance in Greek, an inflected language, was whether readers would pay more attention to inflected function words and to the parts of content words carrying inflections.

\section{Greek Language and Orthography}

An Indo-European language, Greek depends primarily on inflections to denote semantic and syntactic relationships. In modern Greek, the noun, its modifiers, and the verb carry inflections. Noun inflections give information about the gender (masculine, feminine, neuter), the num-

The authors acknowledge their gratitude to the students who participated in this study and to their teachers and school principals. For the preparation of this article we wish to thank the editor, Margaret Jean Intons-Peterson; Michael Turvey; and two other anonymous reviewers for their constructive and helpful comments. For their generous editorial help we want to thank our colleagues Gary Brooks and Ken den Heyer and our friend Wenda Young. Correspondence concerning this article should be addressed to $\mathrm{H}$. F. Chitiri, Department of Education, St. Francis Xavier University, Antigonish, NS, Canada B2G 1 C0 (e-mail: chitirif@essex.stfx.ca).

-Accepted by previous editor, Margaret Jean Intons-Peterson ber (singular, plural), and the case (nominative, genitive, accusative, vocative) of the noun. Verb endings provide information about person and number as well as about the voice and the tense of a verb.

Greek words are typically polysyllabic (Mirambel, 1959). Two-syllable words are most common, followed closely by three-syllable words; four- and five-syllable words occur much less frequently. Function words are usually shorter than content words, having only one or two syllables. Most syllables in Greek are open (Magoulas, 1979) with the predominant pattern being a consonant-vowel syllable.

Greek stress does not have a fixed position: it can be placed on any of the last three syllables of a word, depending on phonological, morphological, and lexical factors (Tombaides, 1986). Stressed syllables are somewhat louder and longer than unstressed syllables, although the difference is not as pronounced as in English. Most Greek words have a single stress, which in written language is indicated by a stress mark over the appropriate syllable. A secondary stress often develops in polysyllabic words when the stressed syllable precedes or follows several unstressed syllables (Joseph \& Philippaki-Warburton, 1987).

The 24-letter alphabet of modern Greek represents 26 phonemes. Sounds are represented directly in the orthography because of the consistency of the letter-to-sound correspondence, in most cases between a phoneme and a single letter. Orthographic variation is permitted for some vowel sounds, which can be represented by different letters or letter combinations. However, a word's spelling provides direct information about its pronunciation because each letter's single sound remains constant in different contexts. 


\section{Orthographic System Effects}

The orthographic depth hypothesis (Feldman \& Turvey, 1983; Katz \& Feldman, 1983) predicts that the phonological code should play a more important role in lexical access in shallow orthographies (e.g., SerboCroatian), which are characterized by an isomorphism between graphemes and phonemes, than in deep orthographies, in which the mapping between spelling and sound is less transparent. This is a dimension on which the orthographies of Greek and English, even though both are alphabetic, differ: Greek orthography is characterized by a more isomorphic relationship between phonemes and graphemes than is English orthography.

Research on English has indicated that in skilled word recognition the phonological code has a lesser role than that of the visual code, mainly because of the complex letter-sound correspondences of the orthography. This complexity renders the phonological pathway slow and unreliable (Coltheart, 1978). As a result, some theorists suggest that the phonological representation of English applies only to the predictable parts of the word-mainly, to consonants and consonant clusters (Carr \& Pollatsek, 1985 ), or to lower frequency words only (Seidenberg, 1985 ). Other theorists propose that the phonological code's role is mainly that of preserving the information in short-term memory (addressed phonology; see Patterson \& Coltheart, 1987).

Research on alphabetic writing systems with a more regular letter-to-sound correspondence than that found in English has suggested a stronger involvement of the phonological code in lexical access. For example, in both lexical decision and naming tasks, Serbo-Croatian readers are influenced more by the phonological forms of the words (Lukatela, Savic, Ognjenovic, \& Turvey, 1978; Lukatela \& Turvey, 1980, 1990), and less by qualities operating on the lexical level, such as semantic priming (Frost, Katz, \& Bentin, 1987) or frequency (Feldman \& Turvey, 1983). Research has likewise indicated a more pronounced role of the phonological code in word recognition in German than in English (Scheerer, 1987).

To study the role of the phonological code in word recognition, we examined the syllable and stress. Syllables are universal properties of speech; they play a major role in the assignment of the phonological rules within the word, providing a framework to its phonological form (Selkirk, 1980). The formation of syllables follows the guidelines for the permissible vowel-consonant combinations in each language. In alphabetic writing systems, information about syllables is reflected to some extent in words' spellings because letter combinations between syllables are less frequent than those within syllables (Adams, 1981).

Recent word recognition models have included syllabic information in both the orthographic and the phonological systems of lexical access (Seidenberg, 1989; Seidenberg \& McClelland, 1989). This information is encoded in terms of letter and phoneme clusters, which are activated through the corresponding letter and phoneme nodes. The extent to which the activated letter and phoneme clusters will correspond to syllabic units depends not only on the saliency of syllables in the language, but also on the transparency of the phonological representations of the orthography. In studies of English word recognition, the use of syllabic units has been found in lower frequency words only (Jared \& Seidenberg, 1990; Seidenberg, 1987, 1989). This tendency seems to be justified not only because of the lack of a uniform syllabic structure in English, but also because of the ambiguity in the sound representation of words. Conversely, in the shallow Serbo-Croatian orthography, syllabic units seem to be involved in the recognition of all words (Katz \& Feldman, 1981).

Stress, the other property upon which we focused, gives critical information not only about a word's correct pronunciation, but also about the retrieval of its phonological form (Colombo, 1992). This information may be especially relevant to word identification in languages in which stress location is not predictable (Black \& Byng, 1986). Stress effects are apparent only when a word's phonological form is assembled on the basis of lettersound correspondences (Colombo, 1992). In such instances, specific syllables may emerge as more decisive and consequently more sensitive to stress location than other syllables. This seems to be true of final syllables in both English (Drewnowski \& Healy, 1982; Goldman \& Healy, 1985; Treiman, Goswami, \& Bruck, 1990) and Italian (Colombo, 1992).

In the present experiment, the orthographic depth hypothesis led us to expect that syllable and stress effects would be more pronounced in Greek than in English word recognition because of the Greek orthography's consistency in representing the sounds of the language.

\section{Language System Effects}

The second aspect of the reading process that we examined was the processing of syntactic information-in particular readers' sensitivity to the syntactic cues available in their language. We based our hypothesis on the competition model (MacWhinney \& Bates, 1989; MacWhinney, Bates, \& Kliegl, 1984), according to which cue strength (a linguistic structure's frequency and reliability in expressing desired functions) plays a major role in speakers' processing of language. On the basis of this model, linguistic structures might differ in importance across languages. This prediction has been confirmed through cross-linguistic studies which have shown that in interpreting sentences, speakers utilize different cues in accordance with the syntactic characteristics of their respective languages (MacWhinney et al., 1984).

In the area of word recognition, support for the competition model comes from studies on the storage and processing of polymorphemic words and function words. In the case of polysyllabic and polymorphemic words in English, certain researchers have proposed that first syllables enjoy a more prominent status than last syllables (Taft, 1979, 1987; Taft \& Forster, 1976). The lesser role 
of the last syllable is supported by studies suggesting that the most effective prime of an inflected word is its root morpheme (Lima \& Pollatsek, 1983) and that the use of an inflected prime has the same facilitative influence on a base verb as does the use of the base verb itself ( Stanners, Neiser, Hernon, \& Hall, 1979). Consequently, some theorists have suggested that inflectional affixes may not be fully represented in memory, but may be appended to roots through the application of rules.

In contrast, research on inflected languages such as Serbo-Croatian and Italian has provided support for the importance of the last syllable in word recognition. In Serbo-Croatian, subjects respond faster to targets in oblique cases when they are primed by an identical prime than when they are primed by another oblique form of the same noun (Feldman, 1987; Feldman \& Fowler, 1987; Feldman, Kostic, Lukatela, \& Turvey, 1983). Similarly in Italian, inflections are an important differentiating factor in reaction time to verbs: subjects' response times vary $(60 \%)$, depending on the number of letters in an inflection (Jarvella, Job, Sandstrom, \& Schreuder, 1987).

Differences in the processing of syntactic information across languages have also been found in the case of function words. Studies in English have suggested that readers pay less attention to function words than to content words. A common finding is that function words, especially the shorter ones such as the, of, and and, are more likely to be skipped than content words of comparable length (Just \& Carpenter, 1980; O'Reagan, 1979). When the letter cancellation paradigm is employed, researchers have found that readers omit more letters in function words than in content words (Corcoran, 1966; Hatch, Polin, \& Part, 1974; Healy, 1976).

Research on the reading of inflected languages, however, has shown that the attention paid by readers to function words is the same as, or even more than, that which they pay to content words. Clarke (1979) found that, in an oral reading task, Spanish readers produced most reading errors on function words. In German, readers exhibited the tendency to fixate longer on function words than on the following content word, a tendency that applied especially to inflected function words such as some forms of the definite article (e.g., der, den; see Bernhardt, 1986).

In accordance with the competition model, we expected that readers of English and Greek would attend to different cues. In particular, Greek readers were expected to attend to a greater extent than would English readers to the processing of inflections in both content and function words, because of the inflected nature of the Greek language.

The general purpose of the present experiment was to study the effect of writing and language system characteristics on the reading process. Two main research questions were addressed: Is the consistency of the orthography in representing the sound of the language a determining factor in the involvement of the phonological code in word recognition? And second, do readers of different languages attend to words or parts of words in accordance with the syntactic characteristics of their respective languages?

The role of the phonological code was studied in relation to students' sensitivity to syllables and stress in twoand three-syllable content words. On the basis of the orthographic depth hypothesis, it was expected that these two phonologically defined features would play a stronger role in Greek than in English.

The impact of syntactic characteristics was examined in relation to the processing of the different parts of content words and of function words. We further examined whether Greek readers would discriminate between inflected and uninflected function words. On the basis of previous research, we expected that such readers would attend particularly to content word endings and to inflected function words. English readers, on the other hand, were expected to attend more to content than to function words and to focus primarily on the beginnings of content words.

The subjects were skilled monolingual English and Greek readers in comparable cities in North America and Greece. The study was undertaken in two phases. First, students' linguistic and reading proficiency was assessed with a battery of pretest measures. Next, these readers' word recognition processes were investigated with a letter cancellation paradigm. Both phases were conducted by the same investigator. The procedures were identical for both student populations, and every effort was made to ensure comparability of materials and instructions.

\section{METHOD}

\section{Subjects}

A total of 137 monolingual subjects participated in this experiment, 72 English- and 65 Greek-speaking students. All attended Grade 10 in public schools and came from middle-class, suburban areas in North America or Greece. The average age was 15 years (age range, 15-17 years). Volunteer participants were given questionnaires on their language use patterns. Only students who spoke the respective languages both within and outside the home, and who participated in all sessions, were included in the sample. The final sample consisted of 105 students, including 53 English ( 33 male and 20 female) and 52 Greek (26 male and 26 female) students.

All were average to above average readers. To ascertain the student subjects' linguistic and reading proficiency, they were given a number of test measures. The linguistic measures tested vocabulary knowledge (Peabody Picture Vocabulary Test-Revised, PPVT-R; Dunn \& Dunn, 1981) and syntactic knowledge (Geva \& Ryan, 1987). The students' reading proficiency was tested in relation to their context-free word recognition (Wide Range Achievement Test-Revised, WRAT-R, Reading; Jastak \& Wilkinson, 1984) and their reading comprehension (Stanford Test of Academic Skills, TASK, Level 1-A-Reading; Gardner, Callis, Merwin, \& Madden, 1972). ${ }^{1}$

The measures were given in the subjects' respective languages. Only the test of syntactic knowledge (Geva \& Ryan, 1987) was available in Greek and had been used previously in research (Katsaiti, 1986). The other tests had to be translated into Greek. The translations were done by a native speaker of Greek who was also highly proficient in English; they were subsequently checked and approved by Greek high school teachers. ${ }^{2}$ 


\section{Psychometric Issues}

On the Reading Comprehension subtest of the widely used Stanford Achievement Test (maximum raw score, 78), the English students $(M=58.66, S D=7.68)$ and Greek students $(M=59.54$, $S D=6.44)$ performed at comparable levels $[F(1,103)<1]$. Performance on this test was almost identical for the two groups, and neither group's performance was near ceiling. All subjects read with comprehension at or above the level that would be expected for their age and grade, so we concluded that both groups consisted of competent readers. This observation was confirmed both by their teachers and by our own experience in testing them in the experiment.

Our pretesting did, however, raise some serious psychometric issues that are implicit in most cross-linguistic reading studies where there are no standardized tests for one or more of the language groups. It was apparent from our pretesting of the students that, because of linguistic and orthographic differences between the languages, "matching"' groups of English and Greek subjects on the basis of linguistic and word recognition test scores is impossible without tests that have been standardized specifically for each linguistic group. This problem was apparent in the translation of the PPVT-R. Because some of the difficult words in English had Greek origins, they were more familiar to Greek than to English students. A significant discrepancy in test performance on the PPVT-R (maximum raw score, 175) between the two groups $[F(1,103)=93.56$, $p<.001$ ], with the English students $(M=141.53, S D=8.10)$ performing considerably below the Greek $(M=157.00, S D=$ 8.29 ), is probably at least as indicative of problems related to establishing a comparable difficulty level between languages as it is of any real differences in linguistic abilities. On the test of syntactic knowledge (Geva \& Ryan, 1987; Katsaiti, 1986; maximum raw score, 30), the Greek students $(M=27.50, S D=2.95$ ) also performed somewhat better than the English students $(M=25.28$, $S D=2.74)[F(1,103)=15.90, p<.001]$, despite the fact that performance on this test in both languages was near ceiling levels. This may reflect, in part, a difference across languages in the relative difficulty of the vocabulary in the test. Although the Greek version of the test had been used once in previous research, neither it nor the English version of the test had undergone standardization procedures.

A different type of problem affected the Greek measure of contextfree word recognition, which was a translation of the WRAT-R Reading subtest (maximum raw score, 89 ). We obtained a very large discrepancy between the English $(M=58.62, S D=6.89)$ and Greek students $(M=88.48, S D=0.89)$ on the WRAT-R $[F(1,103)=959.69, p<.001]$, with the Greek students performing almost at ceiling. Because of the shallow nature of Greek orthography, the students were able to "read" virtually every word by sounding it out, even if they had no idea what the word meant (as was very clear when they were informally asked word meanings). For readers of English, performance dropped drastically once words ceased being familiar. This contrast in the context-free word recognition performance across the two languages simply confirms the distinction between deep and shallow orthographies and points to a problem inherent in any comparison between the two types of orthographies: it is possible for a reader of a shallow orthography to decode virtually any word on the basis of letter-to-sound correspondences.

Although every effort was made to equate the samples on the basis of linguistic and word recognition measures, we learned "the hard way" about problems inherent in such attempts. We have described these problems here to alert future researchers to possible difficulties in cross-linguistic research, in the hope that this awareness will lead to potential solutions.

\section{Task}

The task used in the research was the letter cancellation paradigm. In this task, readers have to cross out every instance of a specific target letter that they notice while they are reading connected text. The underlying assumption for this technique is that readers detect the letters that are processed to a conscious level and miss those that are not. Moreover, target omission is considered to take place more readily when readers form internal representations in the form of units larger than the letter (Healy \& Drewnowski, 1983). In other words, omission patterns are considered to reflect word processing factors (Proctor \& Healy, 1985).

The subjects were given normal printed texts and were explicitly instructed to focus on comprehension and to cross out target letters when they noticed them. As in previous research (Proctor \& Healy, 1985), this precaution was taken to ensure that readers processed the meaning of the texts rather than simply scanned the texts to detect letters.

\section{Materials}

The experimental questions were studied in relation to two passages, each with a different target letter. The letters chosen, $a$ and $o$, have similar relative frequencies in the two languages. (The letter $a$ is the most frequent and $o$ the third most frequent vowel in English, according to Massaro, Taylor, Venezky, Jastrzembski, \& Lucas, 1980, and also in Greek, according to a preliminary count of vowels of words from a Grade 10 reader.)

Two texts were constructed in each language. All the texts were biographies. They were written by the same author and approved of by high school teachers in each country. The texts had approximately the same lengths (2,100 words) and had similar numbers of sentences (mean, 80; range, 78-81) and words per sentence (mean, 26; range, 25.9-26.1). The target letter in each text was contained in a controlled number of words: 135 content words and approximately 300 function words per passage. Examples of the text materials are given in the following excerpts (see Figure 1) with the content and function words containing the target underlined.

The content words included two- and three-syllable words that could have the target letter in any syllable (e.g., carpenter, occasion, registrar). For each syllable position, there was a stressed and an unstressed condition (e.g., taxi, lament). ${ }^{3}$ This manipulation allowed for the study of phonological effects among two- and three-syllable words across the different syllables and permitted the control of effects that are primarily due to target location. The only exception to this pattern was the third syllable of three-syllable words, which was present in the unstressed condition only. The reason for this restriction was that not enough English words met these two criteria (third syllable and stressed) for the target letters under consideration. As a result, there were 135 content words divided into nine categories of 15 words each.

Such a leader was Sam Martin, the big newspaper editor, who was seeking to be a nominee of the Republican Party for the presidential race in November. Sam appeared to be an ideal candidate as he seemed to embody those virtues that many would like to see in a public figure, and besides, nobody could accuse him of being dishonest.

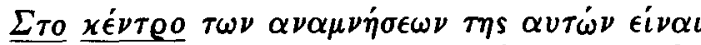

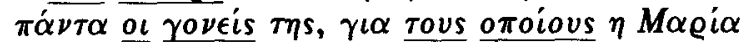

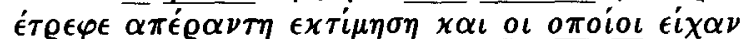

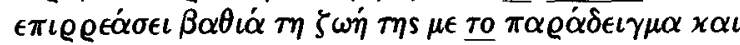

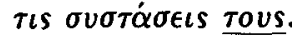

Figure 1. Excerpt from the English and Greek texts with the target letter $o$. 
Words were matched between languages in relation to numbers of letters, so that each English word was paired with a Greek word having the same letter length (4-12 letters). Among three-syllable words, the majority $(71 \%)$ were 7 or 8 letters long, and among two-syllable words, most (78\%) were 5 or 6 letters long. An attempt was also made to equate these words in terms of frequency. Since no frequency lists are available in Greek, the frequency of the English translation of each word was used. Words were classified as low (1-40), medium (41-120), and high frequency (121-472) on the basis of the frequency list of Kucera and Francis (1967). Low-frequency words constituted $65 \%$, medium-frequency words $18 \%$, and high-frequency words $12 \%$ of the words used. Every Greek word was matched with an English word with exactly the same characteristics in terms of number of syllables, target position, stress condition of the syllable containing the target, letter length, and approximate frequency.

Finally, all texts were followed by six comprehension questions in a multiple-choice format. Students who failed to answer three or more out of the six questions correctly were excluded from the sample.

\section{Procedure}

The subjects were trained and tested on the experimental task in three different sessions in their normal classrooms. The first session was a brief training session in which the subjects were familiarized with letter cancellation and with the instructions. In this practice session, in order to avoid any transfer effects, the letter $i$ was used. The materials used for this training session were three short paragraphs, each of which was followed by comprehension questions in a multiple-choice format. In the actual sessions as well, the experimental passage was preceded by a short training paragraph with the same letter as that used in the actual text; this training paragraph too was followed by multiple-choice questions. The instructions given in each session were the same and were similar to those employed by other researchers (e.g., Goldman \& Healy, 1985); the students were asked to focus on comprehension and to cross out every instance of the target whenever they noticed it. They were told further that they should not go back if they realized that they had missed crossing out a letter. During each testing session, a time limit was set on the students' performance, to prevent them from focusing primarily on letter cancellation. This limit was based on extensive pilot testing, with students' speed set at a minimum of 105-110 words per minute. Students who performed below this limit were excluded from the final sample.

\section{Design}

The experiment had three major independent variables: language (English, Greek), target letter $(o, a)$, and word class (content or function). The dependent measure was the omission rate-that is, the number of instances of the target letter that a subject failed to detect. Language (English, Greek) was a between-subjects factor, while letter $(o, a)$ and word class (content or function) were the main within-subjects factors. Overall, the major analysis in relation to word class involved a language $x$ letter $x$ word class or a $2 \times 2 \times 2$ mixed design.

In addition, we analyzed the omission rate among content words only in relation to three additional independent variables: number of syllables (two and three), presence or absence of stress, and position of the target (first, second, or third syllable). In this analysis as well, language (English, Greek) was a between-subjects factor, and the letter under investigation $(a, o)$, the number of syllables (two or three), the presence of stress (present, absent), and the position of the target (first, second, or third syllable) were withinsubjects factors. Overall, the analysis of these three attributes in relation to the omission rate among content words involved a language $\times$ letter $\times$ number of syllables $\times$ stress $\times$ target position or a $2 \times 2 \times 2 \times 2 \times 3$ incomplete crossed design. We used Bonferroni $t$ tests to examine the effects of number of syllables, stress, and target position within each language separately. Moreover, the omission rate among content words was studied with respect to word frequency (low, medium, high), word length, and the position of the word in the sentence.

\section{RESULTS}

The results of the test phase are based on analyses of performance on the letter cancellation paradigm. According to this methodology, detection of a letter is seen as an indication that the letter has been processed to the level of consciousness (Healy, Conboy, \& Drewnowski, 1987). Alternatively, omission of a letter suggests the formation of units larger than the letter. Performance on the letter cancellation task in connection with overall omission and the specific experimental questions studied were analyzed by using analyses of variance (ANOVAs) and planned comparisons. We used Pearson correlations to examine the relationship between letter cancellation on the $o$ and the $a$ text in each language and performance on the comprehension questions following each passage. Finally, we used regression analyses to study the effects of word frequency, word length, and word position on the omission of targets in content words.

\section{Letter Detection}

Only misses (failure to detect the target letter) were counted as omissions, because false alarms (cancellations of nontarget letters) were virtually nonexistent. We counted omissions in a word only once even in the case of some function words that included two instances of the letter under consideration (against for the letter a). Subjects who failed to detect any letters on a whole page or who detected only a minimal number of letters (fewer than the established criterion of $42 \%$ of content words) were excluded from the sample. This was the case for 11 subjects or $16 \%$ from the original North American sample and 12 subjects or $18 \%$ from the original Greek sample. The exclusion of these subjects was considered necessary, because they were not following the task instructions exactly (reading for meaning and simultaneously crossing out targets).

Target omission was analyzed in an ANOVA in relation to the effects of language (English and Greek) and target letter $(a, o)$. Both main effects were significant. Greek students missed more targets overall than did English-speaking students $[F(1,103)=5.89, p<.05]$. Both groups missed more letters when the target was $a$ than when it was $o[F(1,103)=65.60, p<.001]$, suggesting an influence of letter frequency, since $a$ occurs more frequently than $o$ in both orthographies. Moreover, the differential omission rate between the two targets was more pronounced among Greek students, as is suggested by the significant language $\times$ letter interaction $[F(1,103)=$ $4.85, p<.05]$. The higher omission rate in the $a$ passage in Greek could be explained by the higher incidence of missed function words. Since more noninflected function words had the letter $a(67 \%)$ than the letter $o(48 \%)$ in Greek, the higher omission rate could indicate that they 
were processed as units, which is consistent with the previous literature on function words.

\section{Effects of Orthographic System Characteristics}

Information about the role of the orthography was provided by the test of context-free word recognition given prior to the experimental phase. Students' performance on the WRAT-R Reading subtest (Jastak \& Wilkinson, 1984) was very different in English than it was in Greek. The Greek students pronounced almost all words correctly (their mean accuracy was 88.48 out of 89 words), whereas English students experienced difficulties once the words ceased being familiar. In other words, the Greek students confirmed the shallow nature of Greek orthography by their perfect word recognition performance, even decoding words whose meaning was totally unknown to them.

The first main experimental question regarded the effect of the orthographic code, in pursuit of the prediction of the orthographic depth hypothesis that the degree of phonological representation should be reflected in a stronger influence of the phonological code in word recognition. To investigate the involvement of the phonological code, we focused on two phonologically defined factors: syllables and stress. These two factors are closely related, since the presence of stress effects is dependent upon the formation of reading units larger than the letter (Drewnowski \& Healy, 1977).

Processing of syllabic units. To examine the role of syllables, we focused on the first and second syllables of two- and three-syllable content words. The results of the analysis indicate that both groups of subjects were influenced by the number of syllables in a word, which is reflected in a significant main effect of the number of syllables $[F(1,103)=6.78, p<.05]$. The importance of syllabic units, however, seems to differ between the two languages, as is reflected in a significant language $\times$ number of syllables interaction $[F(1,103)=56.81, p<.001]$ (see Figure 2). The Greek students failed to detect more letters in three-syllable words $[t(51)=6.44, p<.001]$, suggesting that their omission pattern was influenced by

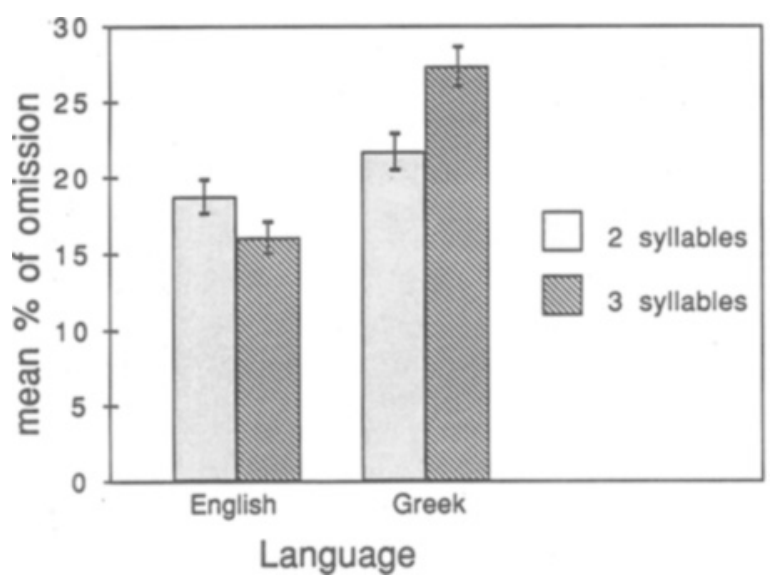

Figure 2. Omission pattern in relation to syllable effects in English and Greek.

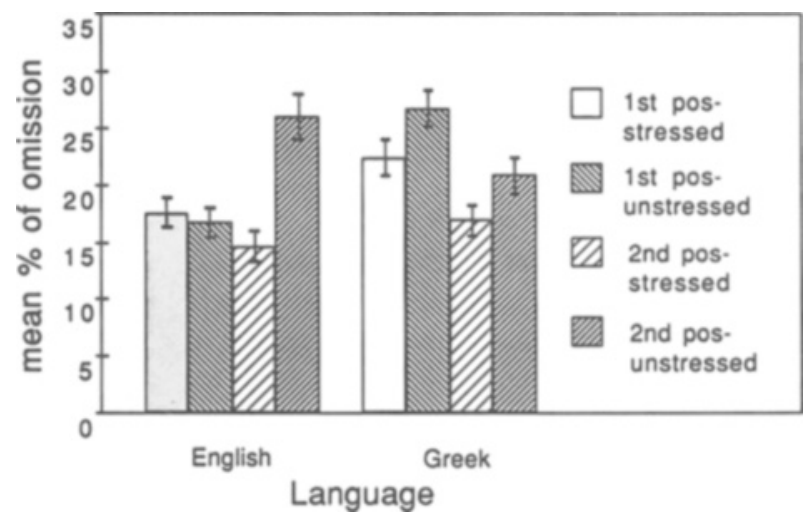

Figure 3. Omission pattern in relation to stress and syllable effects in two-syllable content words in English and Greek.

the processing of longer words with more syllables. English students exhibited the reverse pattern, since they failed to detect more target letters in two- as opposed to three-syllable words [t(52) $=-3.98, p<.001]$. The target letter, whether $a$ or $o$, did not have an effect on the omission pattern in relation to the number of syllables. Since the number of syllables and of letters was controlled in each language, it seems that, in support of the orthographic depth hypothesis, syllabic units do play a stronger role in Greek word recognition than in English.

Role of stress. The results of the analysis of stress effects showed that readers in both languages are influenced by their presence, as is indicated by the significant main effect of stress $[F(1,103)=29.02, p<.001]$. The effects of stress, however, were not uniform across twoand three-syllable words, as is indicated by the stress $x$ number of syllables interaction $[F(1,103)=16.07, p<$ $.001]$. Neither were they uniform between the two syllable positions, whether first or second, as is suggested by the stress $\times$ syllable position interaction $[F(1,103)=$ 20.98, $p<.001]$.

As a result of the different stress effects in relation to number of syllables, separate analyses were undertaken among two- and three-syllable words. Among two-syllable words, stress effects were not evenly distributed between the two syllable positions $[F(1,103)=16.70, p<.001]$. Further, the pattern of stress effects on each syllable was not consistent between the two languages, as is indicated by a significant language $\times$ stress $\times$ syllable position interaction $[F(1,103)=17.79, p<.001]$ (see Figure 3). That is, in Greek, stress effects were present on both the first $[t(51)=-3.46, p<.001]$ and the second syllables $[t(51)=-2.66, p<.01]$. In English, on the other hand, stress effects were limited to the second syllable only $[t(52)=-7.44, p<.001]$. This result in English could in part be a consequence of the linguistic nature of the stimuli; in the present study, English two-syllable words with the target in the stressed second syllable were mainly verbs, whereas words with the target in the unstressed condition were nouns. Thus, the observed stronger stress effects on the second syllable of English two-syllable 


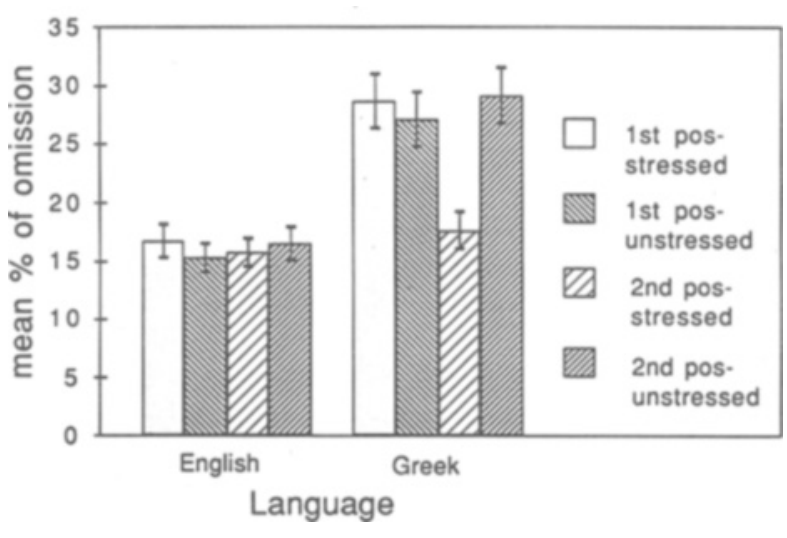

Figure 4. Omission pattern in relation to stress and syllable effects for the first two syllables of three-syllable content words (target letter o) in English and Greek.

words could also indicate that the last syllable of verbs is attended to more than may be the case for the last syllable of nouns.

For three-syllable words, stress was not significant $[F(1,103)=2$, n.s.]. This absence of stress effects applied to both languages, even though, as a marginally significant interaction between language and stress suggested $[F(1,103)=3.68, p<.058]$, stress effects were somewhat more pronounced in Greek. This tendency in Greek was attributed mainly to words having the target $o$, in which case students distinguished between the stressed and the unstressed condition in the second syllable, as is suggested by the significant stress $\times$ position interaction $[F(1,103)=7.40, p<.05]$ (see Figure 4).

On the whole, therefore, it can be said that although readers appear to be sensitive to stress in both languages, stress effects seem to be somewhat more prevalent in Greek than in English. Even though this conclusion appears to support the orthographic depth hypothesis, the fact that stress effects did not apply generally in Greek qualifies its generality.

\section{Effects of Language System Characteristics}

The second major research question regarded the impact of the language system's characteristics on the reading process, to assess the extent to which readers demonstrate sensitivity to the syntactic cues available in their language. In particular, we sought to investigate the prediction of the competition model (MacWhinney et al., 1984) that cue strength (a linguistic structure's frequency and reliability in expressing desired functions) plays a major role in speakers' processing of language. We therefore examined the processing of content versus function words, as well as the processing of the last syllable of content words, which carries inflections in both languages.

The effect of word class. The results indicated that students attended more to the target letters in content words and less to those in function words $[F(1,103)=11.73$, $p<.001]$. Even though, consistent with previous studies, this tendency applied overall to both languages $[F(1,103)<1]$, it was affected by the target letter, as is indicated by a significant triple interaction involving word class, language, and target letter $[F(1,103)=11.05$, $p<.001]$.

Separate analyses further demonstrated that the target letter had a differential effect in each language (see Figure 5). In English, readers demonstrated a tendency to attend less to function words regardless of target $[F(1,51)=$ 3.14 , n.s.]. In Greek, on the other hand, the omission pattern between content and function words was influenced considerably by the target letter $[F(1,50)=51.77$, $p<.001]$. The Greek students tended to differentiate more strongly between content and function words in the case of the letter $a[t(51)=-4.19, p<.001]$. In the case of the letter $o$, however, the Greek students did not differentiate between content and function words. This outcome could be attributed to the fact that $52 \%$ of function words with the letter $o$ were inflected, so that they carried important linguistic information about the following noun. As a result, readers attended more to them, missing fewer letters.

On the basis of these findings, it would seem that readers are indeed influenced by the syntactic characteristics of their language. In English, readers tend to pay less attention to function words overall, whereas Greek readers display this pattern only when the function words are not inflected. In the case of inflected function words, however, Greek readers seem to attend to them to the same extent as they do to content words.

The processing of the last syllable of content words. Syllable position was examined separately for two- and three-syllable words. In both instances, syllable position had a differential effect in each language. Among twosyllable words, this effect was indicated by the significant language $\times$ syllable position interaction $[F(1,103)=$ $23.82, p<.001]$. The Greek students displayed a con-

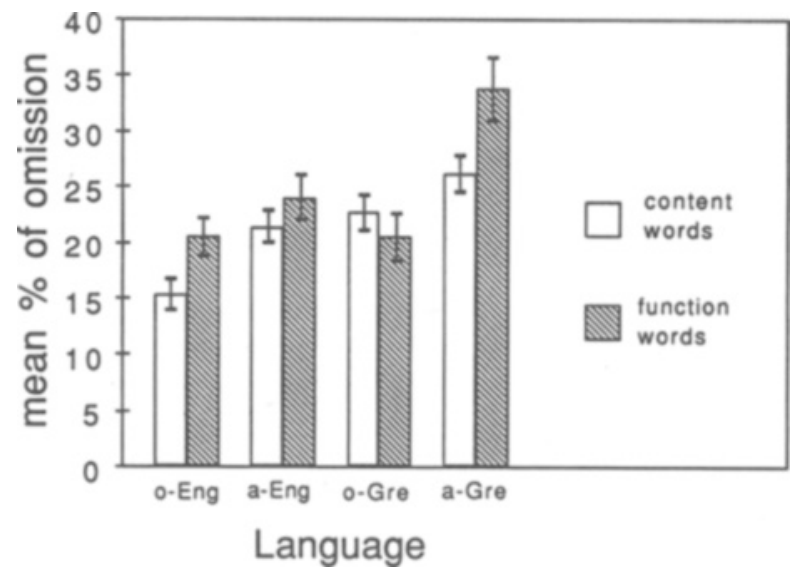

Figure 5. Omission pattern in relation to the processing of content and function words in English and Greek for target letters a and $o$. 


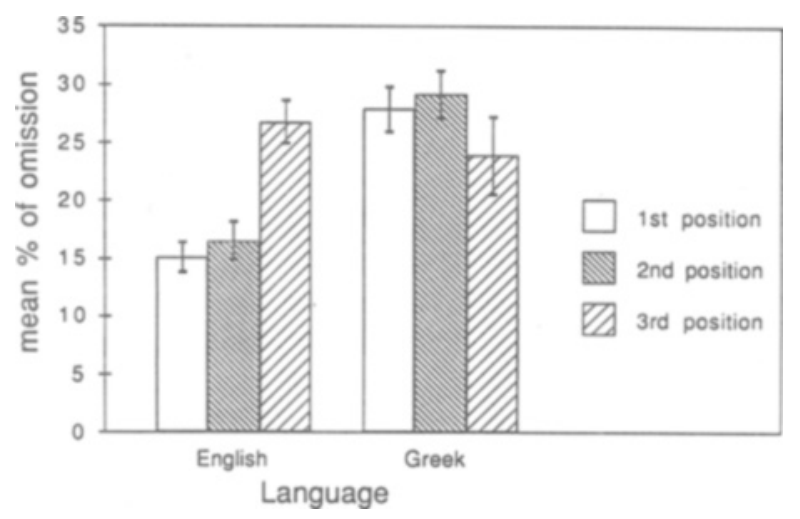

Figure 6. Omission pattern for the three unstressed syllables of three-syllable content words in English and Greek.

sistent pattern of attending more to the second syllable, which carried the inflection. This effect of attending more to the second syllable applied both when this syllable was stressed $[t(51)=3.15, p<.005]$ and when it was unstressed $[t(51)=3.14, p<.005]$. The English-speaking students, on the other hand, differentiated between syllable position, depending upon the presence of stress. When the two syllables were both stressed, the subjects attended more to the second syllable $[t(52)=2.48, p<.05]$; when they were unstressed, they attended more to the first syllable $[t(52)=-5.55, p<.001]$.

Among three-syllable words, the effects of syllable position were studied in the unstressed condition only, since no three-syllable words had the target in the stressed third syllable. The effect of syllable position among the three unstressed syllables of three-syllable words was significant both overall $[F(2,206)=5.73, p<.005]$, and between languages, as is indicated by the significant interaction between syllable position and language $[F(1,103)=$ $30.59, p<.001]$ (see Figure 6). Further comparisons between the three syllable positions indicated that the Greek- and the English-speaking students differed mainly in the relationship between the third syllable and the first $[F(1,103)=39.02, p<.001]$, and between the third syllable and the second $[F(1,103)=43.98, p<.001]$. For the English-speaking students, the third syllable was the one to be processed the least, exhibiting the highest omission rate. This finding applied to the third syllable in relation to the first $[t(52)=-7.13, p<.001]$ as well as to the second syllable $[t(52)=-6.73, p<.001]$. For the Greek students, on the other hand, target letters in the third syllable, which carried the inflection, were missed somewhat less often than those in the first $[t(51)=$ $2.10, p<.05]$ and second $[t(51)=2.96, p<.005]$.

The results of this analysis as well seem to confirm the hypothesis that readers attend more to the parts of the word that carry important syntactic information. As in previous findings, English students had a tendency to at- tend more to the beginning parts of the word. In Greek, however, readers seemed to attend more to the last syllable that carried the inflection; this was consistent with findings for other inflected languages.

\section{Effects of Word Frequency, Word Length, and Position in the Sentence}

Target omission was further analyzed in relation to content word frequency, word length, and the position of the word in the sentence. The importance of the last variable was suggested in a letter cancellation study by Smith and Groat (1979), who found that the sentence position of the word containing the target accounted for a substantial percentage of omissions.

The results of a regression analysis of word length in relation to these three attributes as predictors indicated that the omission rate was indeed influenced by some of the variables studied in English $[F(3,262)=5.21, p<$ $.005]$ as well as in Greek $[F(3,264)=5.38, p<.005]$. Specifically, in both languages these variables accounted for $6 \%$ of the variance. In English, the only variable to exert a significant effect on target omission was word frequency $[F(3,262)=13.08, p<.001]$, with targets in frequent words being missed more than those in less frequent words. In Greek, on the other hand, the variable to account for most of the variance was word length $[F(3,264)=11.44, p<.001]$, with more targets being missed in longer words. Moreover, the effects were of similar magnitude for the $o$ and $a$ passages in both languages.

The effect of word frequency in English could indicate that frequent words are recognized faster and on the basis of fewer features than are less frequent words. Furthermore, their recognition does not require the conscious identification of component letters (Healy et al., 1987). The absence of frequency effects in Greek could be related to a possible discrepancy between the actual frequency of Greek words and the frequency assigned in this study. However, there is also the possibility that the lack of a word frequency effect could be real, because studies of the shallow Serbo-Croatian orthography have shown that naming in this language is affected less by word frequency than is the case in English (Katz \& Feldman, 1983).

\section{DISCUSSION}

In the present study, we set out to examine the nature of the reading process across two different languages and orthographies, in an attempt to gain some insight into the impact that these two dimensions have on reading processes. We studied the influence of the orthographic system in relation to the involvement of two phonological aspects of word recognition: syllable and stress. We examined the effect of the linguistic system with respect to the processing of words in relation to their word class 
(content or function) and to the last syllable of content words in comparison with the other syllables.

The evidence relating to these specific questions indicated that, contrary to previous suggestions, the reading process is not uniform across languages and orthographies. At least at the levels examined, it reflects the sensitivity of the readers to the idiosyncrasies of their orthography and language. This pattern of results is the more significant because it was found in skilled readers in each language, a stage at which differences should have been at a minimum.

\section{The Effect of Orthographic Characteristics on Word Recognition}

Both the visual and the phonological codes are implicated in the word recognition of English and Greek. The effect of the visual code was indicated by the presence of letter frequency effects in the two orthographies (i.e., $a$ is more frequent in both languages than $o$, and it was missed more often), and the involvement of the phonological code was suggested by readers' sensitivity to syllabic and stress factors.

Despite the presence of both codes in the word recognition of the two orthographies, the results also suggest that the involvement of the phonological code may be more pronounced in Greek. This possibility was supported by the more consistent syllabic and stress effects obtained among Greek words and also by the concomitant presence of word length effects on the omission rate. The simultaneous presence of word length and syllabic effects has also been observed in the naming of English lowfrequency words by Jared and Seidenberg (1990), who attributed it to the activation of a word's phonological properties.

The presence of syllabic and stress effects in Greek could also be interpreted in terms of visual encoding. For one thing, syllables can be processed on the basis of a word's orthographic redundancy - that is, on the basis of one's knowledge of the permissible letter coalitions in the word (Adams, 1981; Seidenberg, 1987, 1989). In addition, the presence of stress effects primarily among twosyllable words could be ascribed to visual processes, since stress is also marked visually in Greek. In this case, the absence of stress effects in the first two syllables of threesyllable words could be explained in terms of the lesser processing of the stress mark because of the added load of processing three instead of two syllables (Spoehr \& Smith, 1973).

However, the shallow nature of the Greek orthographywhich was demonstrated in the students' very accurate performance on the test of context-free word recognition (WRAT-R)-makes it more likely that these effects were due to phonological encoding. Such a view is consistent with connectionist models of word recognition such as Seidenberg and McClelland's (1989), according to which the connections between orthographic and phonological units are determined by the nature of the orthography.
In shallow orthographies, such connections are strong because the consistency of the letter-sound correspondences allows for the quick computation of the phonological code in parallel with the orthographic code. Moreover, the present findings on the use of syllabic units in Greek word recognition are in line with similar findings in SerboCroatian (Katz \& Feldman, 1981), in which the phonological code is supposed to be the main route for lexical access (Feldman, 1987; Feldman \& Turvey, 1983; Frost \& Katz, 1989; Katz \& Feldman, 1983; Lukatela et al., 1978; Lukatela \& Turvey, 1990; Turvey, Feldman, \& Lukatela, 1984).

In agreement with previous suggestions (Frederiksen \& Kroll, 1976), the confinement in English of syllabic and stress effects to only the last syllable of two-syllable words seems to indicate the predominance of the visual route in word recognition. This conclusion is also supported by the finding of frequency effects on target omission in the actual texts.

At the same time, the presence of the mentioned phonological effects also suggests that the visual route is not the only one used in English word recognition. Thus, the convergence of syllabic and stress effects on the last syllable of two-syllable words lends some support to theories about the presence of phonological encoding in skilled reading of English (Rubenstein, Lewis, \& Rubenstein, 1971; Spoehr \& Smith, 1973, 1975; Van Orden 1987; Van Orden, Johnston, \& Hale, 1988). According to Seidenberg and McClelland's (1989) connectionist model, the phonological code is always generated in English word recognition even though it is not always used. The reason for the phonological code's more limited input in word recognition is related to the lack of strong correlations between English orthography and phonology, a lack that contributes to weaker weights on the connections between visual and phonological units.

It is possible, however, that the role of the phonological code becomes more prevalent as orthographic information increases and constrains phonological ambiguity, a condition that applies mainly to word endings (Drewnowski \& Healy, 1982). This explanation of the later emergence of the phonological code in English word recognition also seems to be consistent with theories (Kay, 1987; Patterson \& Coltheart, 1987) that support some of the predictions of analogy models (Glushko, 1979). Here a word's pronunciation is formed by analogy to other words that share the same spelling patterns and especially the last three letters with the actual word. In addition, this interpretation of the present results is in agreement with findings on the importance of rime units for the assignment of pronunciation in English (Treiman \& Chafetz, 1987; Treiman \& Zukowski, 1988). The restriction of the phonological code to the last parts of the word could also explain the absence of syllabic and stress effects among the first two syllables of three-syllable words, even though the majority of these words were of low frequency. This absence of phonological effects among lower frequency 
words did not conform to the proposition that low frequency is a prerequisite for phonological encoding in English (Jared \& Seidenberg, 1990; Seidenberg, 1985, 1989). Instead, the present findings suggested that phonological disambiguation may be a more important prerequisite for the use of the phonological code in English, a possibility that could explain the later emergence of the phonological code in word recognition, regardless of frequency.

It would seem, therefore, that both the visual and the phonological codes are involved in the word recognition of the two orthographies, thus supporting models in which both codes play a role (see, e.g., Carr \& Pollatsek, 1985; Seidenberg \& McClelland, 1989). At the same time, however, the extent to which the phonological code is used for lexical access might not be the same in the two orthographies. Specifically, as mentioned earlier, if one is to judge by the more consistent syllabic and stress effects in Greek, the use of a phonological code may be more prevalent in this language than in English. A stronger involvement of the phonological code in the shallow Greek orthography than in the deep English one is in line with the predictions of the orthographic depth hypothesis (Feldman \& Turvey, 1983; Katz \& Feldman, 1983).

The indication that the visual code is also involved in Greek word recognition, as suggested by the presence of letter frequency effects and by the possibility of the visual processing of stress, departs somewhat from the stronger version of the orthographic depth hypothesis, however. One reason for the discrepancy between the Greek results and the Serbo-Croatian ones could be the stronger adherence of the Serbo-Croatian script to the principle of oneto-one letter-to-sound correspondence (Frost et al., 1987). The present findings for Greek may conform more closely to those obtained previously for other orthographies, such as the German, that adhere to the principle of representing the pronunciation of a word while at the same time preserving its morphological affiliation (Scheerer, 1987).

\section{The Effect of Linguistic Characteristics on the Reading Process}

The second question-relating to the effect of linguistic system characteristics on the reading process-also suggests some differences in readers' processes. In this case, the present results confirmed the prediction of the competition model that readers are guided by the nature of their language to process informative cues more than less informative ones (Just \& Carpenter, 1987; MacWhinney \& Bates, 1989; MacWhinney et al., 1984). This tendency was manifested in both languages.

In Greek, this trend was expressed in the deeper processing of inflected function words, as was the case for function words with the target $o$, and for noun endings that carried inflectional affixes. Among nouns, the observed pattern of lower omission on the last syllable both indicated that readers were sensitive to the linguistic information conveyed by this syllable and substantiated pre- vious findings regarding the importance of word endings in the word recognition of inflected languages (Feldman \& Fowler, 1987; Feldman et al., 1983). Moreover, although the stimuli used in the present experiment were on the whole confined to one linguistic class only (nouns), it is likely that similar findings would be observed for other linguistic classes, because of the consistency of the last syllable in carrying the inflection in Greek. Support for this conjecture comes from a study of Italian, also an inflected language, which confirmed the importance of the last syllable for the word recognition of verbs as well (Jarvella et al., 1987).

Readers of English also exhibited selectivity in the cues they processed. In the case of content words, students manifested a tendency to process to a greater extent the beginning parts of the word. Among three-syllable words, this tendency did not apply only to the first syllable, as suggested by Taft (Taft, 1979, 1987; Taft \& Forster, 1976), but also to the second syllable, as observed in other studies (Andrews, 1986; Lima \& Pollatsek, 1983). The inclination to pay attention to both the first and the second syllables of three-syllable words was also supported by the lack of differentiation between these two syllables under stressed and unstressed conditions. Among English two-syllable words, the second syllable may also be involved to a greater extent in word recognition but only in the case of verbs. Although one could infer that the possibility of different processing of nouns and of verbs is another reflection of the impact of linguistic characteristics on word recognition, more research is needed to substantiate this suggestion. With respect to word class, English readers tended to process content words to a greater extent than they did function words, in agreement with the findings in previous studies (Hatch et al., 1974; Healy, 1976; Schindler, 1978; Taylor \& Taylor, 1983).

On the whole, the findings on the impact of language system characteristics suggest that readers' behavior is guided by both universal and language-specific criteria. The first aspect was demonstrated in relation to the tendency to miss target letters in function words more than in content words in both English and Greek, a trend indicating some universal properties that function words share as a class. Such properties could be related to function words' linguistic contribution to meaning, which is similar across languages (Taylor \& Taylor, 1983), as well as to their frequency and to their physical appearance (brevity). Because of the latter two characteristics, it might be that function words are processed as units (Healy, 1980; Healy \& Drewnowski, 1983) or that they are processed concurrently with the previous content word (Just \& Carpenter, 1980, 1987).

The use of language-specific criteria was demonstrated, on the other hand, in the Greek readers' differential processing of inflected and uninflected function words. As mentioned previously, when processing inflected function words, the Greek readers attended to them to the same extent as they did to content words. When the function 
words were uninflected, on the other hand, these readers attended to them considerably less than to content words displaying the same pattern as in English. On the basis of this result, one can infer that not all function words, but rather only inflected ones, are processed at a deeper level in inflected languages. This suggestion confirms Bernhardt's (1986) findings for German.

Another indication of the use of language-specific criteria is related to the different patterns exhibited by the two language groups in the processing of content words. Regarding this tendency, the results provided evidence contrary to Taft's $(1979,1987)$ generalization about the uniqueness of the first syllable or basic orthographic syllable structure for word recognition. Thus, although his hypotheses may be relevant to English, they appear not to apply to Greek, in which the last syllable also seems to influence lexical access. In addition, although the present findings cannot provide direct evidence concerning the memory representation of words in each language, they can nevertheless offer some suggestions. In Greek, for example, as in Serbo-Croatian (Feldman \& Fowler, 1987; Feldman et al., 1983), it is possible that lexical entries are fully represented in memory, as is suggested by the importance of the last syllable. If this hypothesis is true, it conflicts with the proposition that words are represented in memory through the first syllable only (Taft, 1979, 1987; Taft \& Forster, 1976). In English, too, memory representation of longer words seems to incorporate more than the first syllable, as is suggested by the lack of differentiation between the first and the second syllables of three-syllable words under stressed and unstressed conditions. Moreover, the results of the differential treatment of two-syllable nouns and verbs in English could be an indication of the different memory representations of these two word types in memory. At this point, however, these suggestions can only be speculative, and more research is needed to validate them.

\section{REFERENCES}

ADAMS, M. J. (1981). What good is orthographic redundancy? In O. J. Tzeng \& H. Singer (Eds.), Perception of print: Reading research in experimental psychology (pp. 197-221). Hillsdale, NJ: Erlbaum.

ANDREws, S. (1986). Morphological influences on lexical access: Lexical or nonlexical effects? Journal of Memory \& Language, 25, 174-188.

BernhardT, E. B. (1986). Cognitive processes in L2: An examination of reading behaviors. In J. Lantolf \& A. Labarca (Eds.), Second language acquisition in the classroom setting (pp. 35-50). Norwood, NJ: Ablex.

Black, M., \& Byng, S. (1986). Prosodic constraints in lexical access in reading. Cognitive Neuropsychology, 3, 369-409.

CARr, T. H., \& Pollatsex, A. (1985). Recognizing printed words: A look at current models. In D. Besner, T. G. Waller, \& G. E. MacKinnon (Eds.), Reading research: Advances in theory and practice (Vol. 5, pp. 1-82). Orlando, FL: Academic Press.

Clarke, M. A. (1979). Reading in Spanish and English: Evidence from adult ESL students. Language Learning, 29, 121-150.

CоLомво, L. (1992). Lexical stress effect and its interaction with frequency in word pronunciation. Journal of Experimental Psychology: Human Perception \& Performance, 18, 987-1003.
Coltheart, M. (1978). Lexical access in simple reading tasks. In G. Underwood (Ed.), Strategies of information processing (pp. 151216). London: Academic Press.

CorCoran, D. W. (1966). An acoustic factor in letter cancellation. Nature, $210,658$.

Drewnowski, A., \& Healy, A. F.(1977). Detection errors on the and and: Evidence for reading units larger than the word. Memory \& Cognition, 5, 636-647.

Drewnowski, A., Healy, A. F. (1982). Phonetic factors in letter detection: A reevaluation. Memory \& Cognition, 10, 145-154.

DunN, L. M., \& DunN, L. M. (1981). Peabody Picture Vocabulary Test-Revised. Circle Pines, MN: American Guidance Service.

Feldman, L. B. (1987). Phonological and morphological analysis by skilled readers of Serbo-Croatian. In A. Allport, D. G. MacKay, W. Prinz, \& G. Scheerer (Eds.), Language perception and production (pp. 197-209). London: Academic Press.

Feldman, L. B., \& Fowler, C. A. (1987). The inflected noun system in Serbo-Croatian: Lexical representation of morphological structure. Memory \& Cognition, 15, 1-12.

Feldman, L. B., Kostic, A., Lukatela, G., \& Turvey, M. T. (1983). An evaluation of the "basic orthographic syllabic structure" in a phonologically shallow orthography. Psychological Research, 45 , 55-72.

Feldman, L. B., \& TuRvey, M. T. (1983). Word recognition in SerboCroatian is phonological analytic. Journal of Experimental Psychology: Human Perception \& Performance, 9, 414-420.

FreDeriksen, J. R., \& KRoLL, J. F. (1976). Spelling and sound: Approaches to the internal lexicon. Journal of Experimental Psychology: Human Perception \& Performance, 2, 361-379.

Frost, R., \& KATZ, L. (1989). Orthographic depth and the interaction of visual and auditory processing in word recognition. Memory \& Cognition, 17, 302-310.

Frost, R., Katz, L., \& Bentin, S. (1987). Strategies for visual word recognition and orthographical depth: A multilingual comparison. Journal of Experimental Psychology: Human Perception \& Performance, 13, 104-115.

Gardner, E. F., Callis, J. C., Merwin, J. C., \& Madden, R. (1972). Stanford Test of Academic Skills. New York: Harcourt, Brace, Jovanovich.

Geva, E., \& RyAN, E. B. (1987, June). Linguistic and memory correlates of academic skills in first and second language. Paper presented at the meeting of the Canadian Psychological Association, Vancouver.

GLushKo, R. J. (1979). The organization and activation of orthographic knowledge in reading aloud. Joumal of Experimental Psychology: $\mathrm{Hu}$ man Perception \& Performance, 5, 657-673.

Goldman, H. B., \& Healy, A. F. (1985). Detection errors in a task with articulatory suppression: Phonological recoding and reading. Memory \& Cognition, 13, 463-468.

Hatch, E., Polin, P., \& ParT, S. (1974). Acoustic scanning and syntactic processing: Three reading experiments with first and second language learners. Journal of Reading Behavior, 6, 235-242.

Healy, A. F. (1976). Detection errors on the word the: Evidence for reading units larger than letters. Journal of Experimental Psychology: Human Perception \& Performance, 6, 403-409.

Healy, A. F. (1980). Proofreading errors on the word the: New evidence on reading units. Joumal of Experimental Psychology: Human Perception \& Performance, 6, 403-409.

Healy, A. F., Conboy, G. L., \& Drewnowski, A. (1987). Characterizing the processing units of reading. In B. K. Britton \& S. M. Glynn (Eds.), Executive control processes in reading (pp. 279-296). Hillsdale, NJ: Erlbaum.

HeAly, A. F., \& DREwnowski, A. (1983). Investigating the boundaries of reading units: Letter detection in misspelled words. Journal of Experimental Psychology: Human Perception \& Performance, 9 , 413-420.

JARED, D., \& Seidenberg, M. (1990). Naming multisyllabic words. Journal of Experimental Psychology: Human Perception \& Performance, 16, 92-105.

JarVella, R. J., Job, R., SANdStrom, G., \& Schreuder, R. (1987). 
Morphological constraints on word recognition. In A. Allport, D. G. Mackay, W. Prinz, \& G. Scheerer (Eds.), Language perception and production (pp. 245-262). London: Academic Press.

JASTAK, S., \& Wilkinson, G. S. (1984). Wide Range Achievement Test-Revised. Wilmington, DE: Jastak Associates.

JosePh, B. D., \& PhilipPaKi-Warburton, I. (1987). Modern Greek. London: Croom Helm.

Just, M. A., CARpenter, P. A. (1980). A theory of reading: From eye fixations to comprehension. Psychological Review, 87, 329-354.

JUST, M. A., \& CARPENTER, P. A. (1987). The psychology of reading and language comprehension. Boston: Allyn \& Bacon.

KATSAITI, L. (1986). Remembering, forgetting, and cueing of text in monolinguals and bilinguals. Unpublished doctoral dissertation, University of Toronto.

Katz, L., \& Feldman, L. B. (1981). Linguistic coding in word recognition: Comparison between a deep and a shallow orthography. In A. Lesgold \& C. A. Perfetti (Eds.), Interactive processes in reading (pp. 85-106). Hillsdale, NJ: Erlbaum.

KaTZ, L., \& FeldmaN, L. B. (1983). Relation between pronunciation and recognition of printed words in deep and shallow orthographies. Journal of Experimental Psychology: Learning, Memory, \& Cognition, 9, 157-166.

KAY, J. (1987). Phonological codes in reading: Assignment of sub-word phonology. In A. Allport, D. G. Mackay, W. Prinz, \& E. Scheerer (Eds.), Language perception and production (pp. 181-196). London: Academic Press.

KuČERA, H., \& Francis, W. N. (1967). Computational analysis of present-day American English. Providence, RI: Brown University Press.

Lima, S. D., \& Pollatsek, A. (1983), Lexical access via an orthographic code? The basic orthographic syllabic structure (BOSS) reconsidered. Journal of Verbal Learning \& Verbal Behavior, 22, 310-332.

Lukatela, G., Savic, M. D., Ognjenovic, P., \& Turvey, M. T. (1978). On the relation between processing the Roman and the Cyrillic alphabets: A preliminary analysis with bi-alphabetical readers. Language \& Speech, 21, 113-141.

LUKATEla, G., \& TuRvey, M. (1980). Some experiments on the Roman and Cyrillic alphabets. In J. F. Kavanagh \& R. C. Venezky (Eds.), Orthography, reading and dyslexia (pp. 227-247). Baltimore: University Park Press.

Lukatela, G., \& Turvey, M. T. (1990). Phonemic similarity effects and prelexical phonology. Memory \& Cognition, 18, 128-152.

MACWHINNEY, B., \& BATES, E. (Eds.) (1989). The cross linguistic study of sentence processing. Cambridge: Cambridge University Press.

MacWhinney, B., Bates, E., \& KLIEgl, R. (1984). Cue validity and sentence interpretation in English, German, and Italian. Journal of Verbal Learning \& Verbal Behavior, 23, 127-150.

Magoulas, G. (1979). Introduction to Modern Greek phonology. Athens: University of Athens Press.

Massaro, D. W., Taylor, G. A., Venezky, R. L., Jastrzembski, P., \& LuCAS, P. A. (1980). Letter and word perception. Amsterdam: Elsevier, North-Holland.

Mrrambel, A. (1959). La langue grecque. Paris: Librairie C. Klincksieck.

O'REGAN, K. (1979). Saccade size control in reading: Evidence for the linguistic control hypothesis. Perception \& Psychophysics, 25, 501-509.

Patterson, K., \& Coltheart, V. (1987). Phonological processes in reading: A tutorial review. In M. Coltheart (Ed.), Attention and performance XII: The psychology of reading (pp. 421-447). Hillsdale, NJ: Erlbaum.

Proctor, J. D., \& Healy, A. F. (1985). A secondary task analysis of a word familiarity effect. Journal of Experimental Psychology: $\mathrm{Hu}$ man Perception \& Performance, 11, 286-303.

Rubenstein, H., LeWIs, S. S., \& Rubenstein, M. H. (1971). Evidence for phonemic recoding in visual word recognition. Journal of Verbal Learning \& Verbal Behavior, 7, 645-657.

SCHEERER, E. (1987). Visual word recognition in German. In A. All- port, D. MacKay, W. Prinz, \& E. Scheerer (Eds.), Language perception and production (pp. 227-244). London: Academic Press.

SCHINDLER, R. M. (1978). The effect of prose context on visual search for letters. Memory \& Cognition, 6, 124-130.

SEIDENBERG, M. S. (1985). The time course of phonological code activation in two writing systems. Cognition, 19, 1-30.

SEIDENBERG, M. S. (1987). Sublexical structures in visual word recognition: Access units of orthographic redundancy? In M. Coltheart (Ed.), Attention and performance XII: The psychology of reading (pp. 245-263). Hillsdale, NJ: Erlbaum.

SeIDENBERG, M. S. (1989). Reading complex words. In G. N. Carlson, \& M. K. Tanenhaus (Eds.), Linguistic structure in language processing (pp. 53-105). Dordrecht, The Netherlands: Kluwer Academic Publishers.

Seidenberg, M. S., \& MCClelland, J. L. (1989). A distributed developmental model of word recognition and naming. Psychological Review, 96, 523-568.

SELKIRK, L. (1980). On prosodic structure and its relation to syntactic structure. Bloomington: Indiana University Linguistics Club.

SMith, P. T., \& GroAt, A. (1979). Spelling patterns, letter cancellation and the processing of text. In P. A. Kolers, M. E. Wrolstad, \& H. Bouma (Eds.), Processing of visible language (pp. 309-325). New York: Plenum.

SPOEHR, K. T., \& SMITH, E. E. (1973). The role of syllables in perceptual processing. Cognitive Psychology, 5, 71-89.

SPOEHR, K. T., \& SMITH, E. E. (1975). The role of orthographic and phonotactic rules in perceiving letter patterns. Journal of Experimental Psychology: Human Perception \& Performance, 104, 21-34.

Stanners, R. F., Neiser, W. P., Hernon, W. P., \& Hall, R. (1979). Memory representation for morphologically related words. Journal of Verbal Learning \& Verbal Behavior, 18, 399-412.

TAFT, M. (1979). Lexical access via an orthographic code: The basic orthographic syllabic structure (BOSS). Journal of Verbal Learning \& Verbal Behavior, 18, 21-39.

TAFT, M. (1987). Morphographic processing: The BOSS re-emerges. In M. Coltheart (Ed.), Attention and performance XII: The psychology of reading (pp. 265-279). Hillsdale, NJ: Erlbaum.

TAFT, M., \& FORSTER, K. I. (1976). Lexical storage of polymorphemic and polysyllabic words. Journal of Verbal Learning \& Verbal Behavior, 15, 607-620.

TAYLOR, I., \& TAYLOR, M. M. (1983). The psychology of reading. NeW York: Academic Press.

TомвAIDEs, D. E. (1986). Epitomi tis historias tis hellenikis glossas [Compendium of the history of the Greek language]. Athens: Organismos Ekthoseos Didaktikon Vivlion.

Treiman, R., \& ChafeTz, J. (1987). Are there onset and rime-like units in printed words? In M. Coltheart (Ed.), Attention and performance XII: The psychology of reading (pp. 281-298). Hillsdale, NJ: Erlbaum.

Treiman, R., Goswami, U., \& BRUCK, M. (1990). Not all nonwords are alike: Implications for reading development and theory. Memory \& Cognition, 18, 559-567.

TreimaN, R., \& ZUKOWSKI, A. (1988). Units in reading and spelling. Journal of Memory \& Language, 27, 466-477.

Turvey, M. T., Feldman, L. B, \& Lukatela, G. (1984). The SerboCroatian orthography constrains the reader to a phonologically analytic strategy. In L. Henderson (Ed.), Orthographies and reading (pp. 81-90). London: Erlbaum.

VAN ORden, G. C. (1987). A ROWS is a ROSE: Spelling, sound, and reading. Memory \& Cognition, 15, 181-198.

VAN ORDEn, G. C., Johnston, J. C., \& Hale, B. L. (1988). Word identification in reading proceeds from spelling to sound to meaning. Journal of Experimental Psychology: Learning, Memory, \& Cognition, 14, 371-386.

\section{NOTES}

1. This older version was preferred because it was thought that the newer (1982) version contained information that is culture specific. 
2. In an attempt to ensure comparability of test items we translated these three tests back into English. There was a correspondence of $70 \%$ between the original WRAT-R and PPVT-R English tests and the version that was created after the Greek tests were retranslated into English. This less than perfect correspondence reflects a problem inherent in translation-namely, that it is difficult to establish a one-to-one translation between languages because the same concept can be expressed through several synonyms, especially in the absence of context. When a context is present, as with the reading comprehension test of the Stan ford Achievement Test, equivalence of translation is often difficult to establish because of the differing semantic and syntactic patterns across languages. In this case, while the meaning is the same, the form through which the meaning is conveyed may be different.

Because of these limitations and because there are no Greek word frequency lists, we cannot claim that the tests we used were "equiva- lent" in a technical sense. Their comparability lies in the fact that they covered the same concepts/meanings, using age appropriate vocabulary, as judged by the researchers and teachers involved in the study.

3 . Out of the 270 content words (135 for each text) used in the experimental passages, only 3 English words had more than one stress pattern (conduct, combat, and record). However, the correct pronunciation should be obvious from the sentence context. In Greek, there were 6 words that could be pronounced in two ways, depending on the position of the stress. Given the fact that Greek stress is directly marked in the word, confusion over which pronunciation to choose should be nonexistent.

(Manuscript received December 24, 1992; revision accepted for publication July 30,1993 .) 